\title{
Mechanical Investigation of Epoxy Based High- Strength Carbon Fiber Braided Composites Modified with Silane Coupling Agents
}

OĞUZ ERYILMAZ ( $\square$ oguz.eryilmaz@marmara.edu.tr)

Marmara University - Goztepe Campus: Marmara Universitesi https://orcid.org/0000-0003-0005-1142 Erhan SANCAK

Marmara University - Goztepe Campus: Marmara Universitesi

\section{Original Article}

Keywords: Carbon Fiber, Braiding, Mechanical Properties, Silane Coupling Agents, Composite

Posted Date: July 8th, 2021

DOl: https://doi.org/10.21203/rs.3.rs-678537/v1

License: (c) (i) This work is licensed under a Creative Commons Attribution 4.0 International License.

Read Full License 


\title{
Mechanical Investigation of Epoxy Based High-Strength Carbon Fiber Braided Composites Modified with Silane Coupling Agents
}

Oguz Eryilmaz ${ }^{1^{*}}$ and Erhan Sancak ${ }^{1}$

${ }^{1}$ Department of Textile Engineering, Marmara University, Istanbul, Turkey

*Corresponding author: Department of Textile Engineering, Faculty of Technology, Marmara

University, Kadikoy, Istanbul, 34720 Turkey

e-mail:oguz.eryilmaz@marmara.edu.tr

\begin{abstract}
Braiding technique is one of the most cost-effective and versatile methods to manufacture braided preforms for producing textile reinforced composites which have been utilized in a number of applications such as aerospace and automotive sectors. Carbon fiber is one of the most common reinforcing fibers having high strength and modulus used in high-performance composites. In this study, epoxy resin was modified with 3 - aminopropyltriethoxysilane (APTES) and 3 - aminopropylmethyldimethoxysilane (APMDMS) in order to enhance interfacial adhesion between matrix and carbon fiber. Composites were produced by vacuumassisted resin infusion method (VARIM) using braided carbon fabrics and epoxy resin which was treated with silane at different concentrations (from $0.0 \%$ to $1.0 \%$ ). Braided fabrics were manufactured from a high-strength standard modulus type of carbon fiber and using a radial braiding machine. According to the mechanical results, the ideal (optimum) concentration of APTES and APMDMS for the matrix modification has been around $0.5 \mathrm{wt} \%$ of the epoxy system. Also, the mechanical properties of APTES-treated epoxy composites are slightly higher than those of APMDMS-treated epoxy composites at the same concentration. When it is compared to silane untreated composite, $0.5 \mathrm{wt} \%$ of APTES/APMDMS silane treated epoxy/carbon braided composites have led to an increase of 7.71/6.16 and 7.65/6.05\% in tensile and flexural strength while the corresponding increase has resulted in 17.48/13.51 and $16.63 / 13.33 \%$ in terms of tensile and flexural modulus, respectively. Impact testing results indicate that $0.5 \mathrm{wt} \%$ of APTES and APMDMS composites are improved 6.87 and $4.31 \%$ compared to untreated composites, respectively.
\end{abstract}


Keywords: Carbon Fiber; Braiding; Mechanical Properties; Silane Coupling Agents; Composite

\section{INTRODUCTION}

Textile composites are very attractive because of their superior mechanical properties. So, they have been widely used in aeronautical, automotive, petroleum, maritime, defense, and sports industries among others [1,2]. Carbon fiber composites are ideal for applications where strength, stiffness, lower weight, and superior fatigue properties have critical pre-requisites[3, 4]. Braiding, in general, is a textile manufacturing process in which three or more yarns are interlaced (in the longitudinal direction) to obtain a stronger or thicker product. Braids may be linear, rounded, plane-shell, or solid structures (1-D, 2-D, or 3-D fabrics) with constant or variable cross-section [5]. Two-dimensional (2D) biaxial and three-dimensional (3D) braided fabric structures are frequently used in the aerospace, automotive, and medical industries as structural elements [6,7]. Braiding is recognizable from the other conventional textile processes such as weaving and knitting, in the textile method approaches to produce yarns into a fabric, and in the peculiarity fiber architectures stemming from those methods [8].

A weak fiber-matrix interfacial adhesion can affect adversely the mechanical performance properties of the textile reinforced composites because of the surface incompatibility between hydrophilic carbon fiber and non-polar resin system [5]. So, the relationship between matrix system and carbon fiber is very important to the mechanical properties of carbon fiber composites. As a consequence, a proper interphase process is required to attain enhancements within the mechanical properties of the composites.

It was proposed by many researchers that poor interfacial adhesion ends up with matrix crack, deflection, and fiber pull-out, which were the cornerstone mechanisms for brittle-matrix fiberreinforced composite structures $[9,10]$. This brittle fracture mechanism is one of the disadvantages of carbon fiber composites especially epoxy-based ones [11]. Epoxy resins are a very common type of matrix system that can be curable by some reaction of oxirane groups. 
There is a wide range of organo-functional silane coupling agents that can work with epoxy resins effectively. However, it needs to be certain generalizations that can be made for selecting the ideal silane for the desired structure [12-14].

Silane coupling agent has double functional groups which can form a bridge between the epoxy resin and carbon fiber to enhance the synergy. The use of silane coupling agents to modify the matrix system has many advantages. One of them is that alkoxysilane groups may react with fiber surface and they have a vast number of functional groups that can be adjusted depending on the matrix to be employed. Thus, a silane coupling agent can be used to modify the resin as a chemical method that promotes the interfacial adhesion between matrix and fiber leading to improved mechanical properties of composites $[9,10,15,16]$.

Many studies are related to silanization effects on mechanical properties of woven glass, carbon, or hybrid fabric composites. However, there aren't many studies on braided composites modified with silane coupling agents or a very small amount of work is done to evaluate it. So, in this present study, braided carbon composites were manufactured with high-strength carbon fibers and modified with silane coupling agents which were 3-aminopropyltriethoxysilane (APTES) and 3-aminopropylmethyldimethoxysilane (APMDMS). Mechanical testing (tensile, flexural, and impact) of these composites was carried and the effects of silane coupling treatment on the mechanical properties of the epoxy/carbon braided composites were discussed. The chemical composition of silane coupling agents and epoxy/carbon braided composites were analyzed by Fourier transform infrared spectroscopy (FTIR). The fracture surfaces of these composites obtained from impact analysis were studied with the help of Scanning Microscope Analysis (SEM). 


\section{MATERIALS and METHODS}

\section{Production of the Reinforcement System}

The braided carbon fabrics used in this study were produced with Herzog RF/144-100 machine at ITA (Institut für Textiltechnik) RWTH Aachen University. T700-24K standard modulus carbon fiber supplied by Toray Company, Japan was used in the production of fabrics (Tab. 1).

Table 1. The properties of constituent materials of the braided fabric

\begin{tabular}{|c|c|c|c|c|c|c|}
\hline Material & Type & $\begin{array}{c}\text { Filament } \\
\text { Diameter }\end{array}$ & Density & $\begin{array}{c}\text { Tensile } \\
\text { Strength }\end{array}$ & $\begin{array}{c}\text { Tensile } \\
\text { Modulus }\end{array}$ & $\begin{array}{c}\text { Strain at } \\
\text { Failure }\end{array}$ \\
\hline $\begin{array}{c}\text { Non- Twisted } \\
\text { Carbon Fiber }\end{array}$ & $\mathrm{T} 700$ & $7 \mu \mathrm{m}$ & $1.80 \mathrm{~g} / \mathrm{cm}^{3}$ & $4900 \mathrm{MPa}$ & $230 \mathrm{GPa}$ & $\% 2.1$ \\
\hline
\end{tabular}

In order to manufacture a carbon braided fabric structure, there must be two sets of carbon fiber that are intertwined. The final structure is aligned at some angle to the longitudinal axis of the braided fabric. Two sets of carbon fiber bobbins are identical but have counter direction at any area along the braid. Carbon fiber bobbin from one set does not intersect with any others in the same set but intersects every carbon fiber bobbin in the other set. Each set of carbon fibers in the braiding system are moved at the same speed. In order to produce regular braided pattern fabric, all carbon fiber red bobbins within one set are moved in the clockwise direction while the yellow bobbins in the other set are moved in the counter-clockwise direction (Fig. 1).
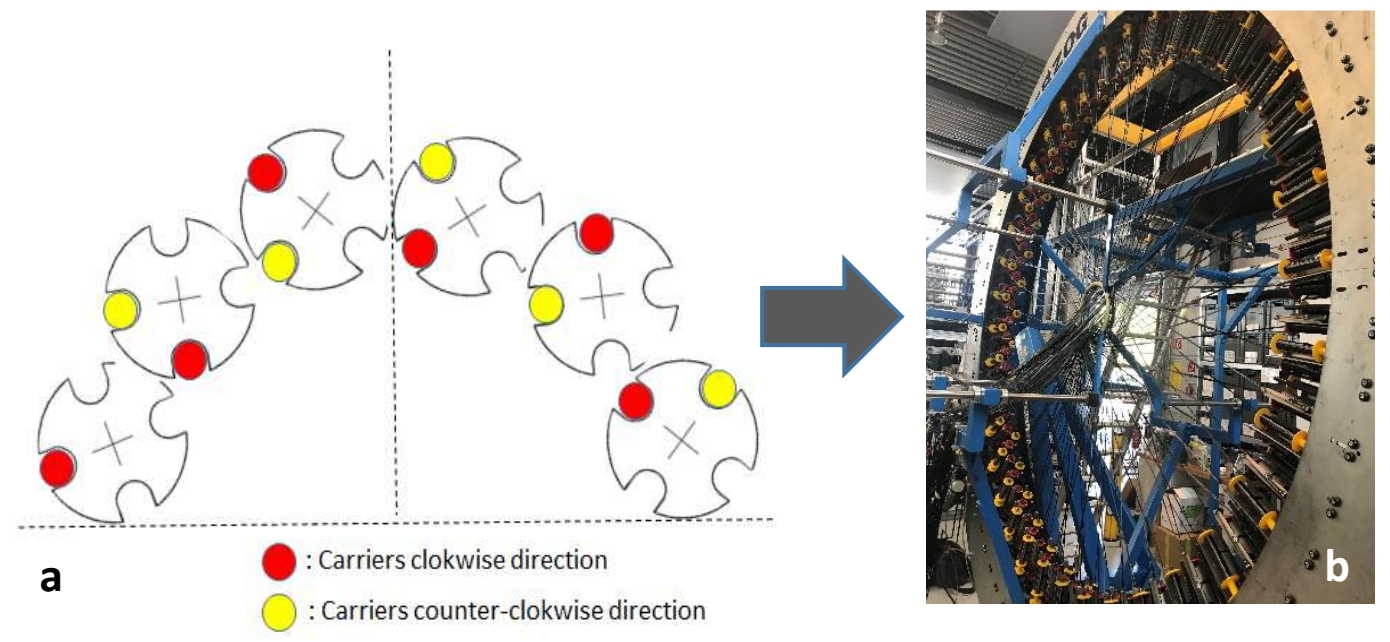
Figure 1. a) The movement of the braid carriers for the production of the regular $2 \times 2$ braided fabric pattern; b) Full deposition of the RF 144-100 braiding machine

To produce the intertwining of the two sets of carbon fiber bobbins, there has to be a motion where some of the bobbins in each set have proceeded toward the center of the tubular mandrel and the rest toward the outside synchronically. Carbon fiber is moving in and out in the radial direction and it is also moving along the circumference of the tubular mandrel. The angular velocity of the braiding carriers is specified as $\omega$. The braiding mandrel is taken forward by a pulling (take-up) mechanism. The take-up speed of the mandrel is specified as $v$. In the case of the tubular mandrel, the relationship between the take-up speed of the mandrel ( $v)$, the rotational speed $(\omega)$ of the bobbin carriers, and the mandrel radius $(\mathrm{R})$ is written by Equation 1 [17-19].

$\theta=\arctan \left(\frac{\omega R}{v}\right) \quad$ Eq. 1. [19]

2D braiding structures can be open or closed meshed architectures which are characterized by coverage factor that means the measure of the surface area enclosed by strands [20]. Since the number and width of fiber (such as $1 \mathrm{~K}, 3 \mathrm{~K}, 6 \mathrm{~K}, 12 \mathrm{~K}, 24 \mathrm{~K}$ ) cannot be changed easily, the coverage factor is obtained by changing the braiding angle corresponding to the change of mandrel diameter [21]. Equation 2 is given for tubular mandrels.

$\mathrm{CF}($ Coverage Factor $)=1-\left(1-\frac{W_{y} N_{c}}{4 \pi R \cos \theta}\right)^{2} \quad$ Eq. 2. [19]

- $\quad N_{\mathrm{c}}$ : Total number of the bobbin carriers

- $\quad W_{\mathrm{y}}$ : Width of the fiber

- $\quad$ R: Diameter of the mandrel

The prepared samples for this particular case were braided on a mandrel by the braiding robot. Each ply was braided once, cut, and stacked on top of another one. Even though the adjustment is meant to be $45^{\circ}$ in orientation, the human error may vary between $\pm 5^{\circ}$ (Fig. 2). Other properties of the braided carbon fabric are shown in Table 2. 


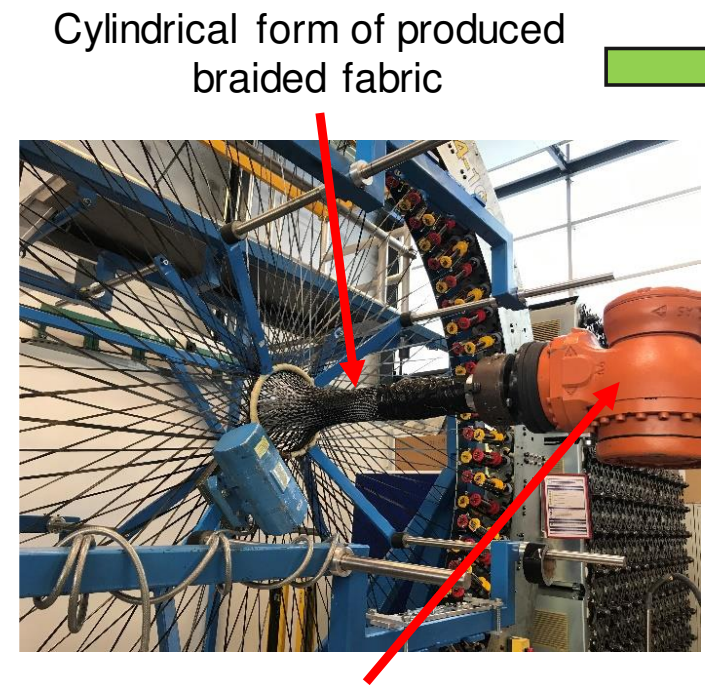

Take-up Mechanism: Robotic Arm
Cut version of braided fabric

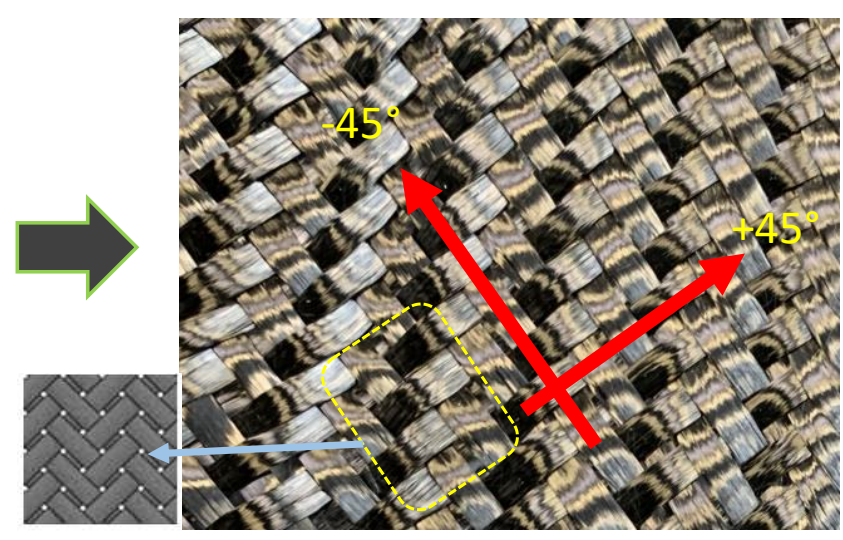

b) Regular $2 \times 2$

Regular 2x2 braided pattern fabric

Figure 2. The production of the regular $2 \times 2$ pattern braided fabric

Table 2. Properties of the produced braided carbon fabric used in the reinforcement system

\begin{tabular}{|c|c|c|c|c|}
\hline Type of Fabric & Weight $\left(\mathrm{g} / \mathrm{m}^{2}\right)$ & $\begin{array}{c}\text { Filament } \\
\text { Number/Yarn } \\
\text { Number }\end{array}$ & Fabric Pattern & Fabric Thickness \\
\hline Braided Carbon & 912.38 & $24 \mathrm{~K} / 1650$ tex & $2 \times 2$ Regular & $0.55 \mathrm{~mm}$ \\
\hline
\end{tabular}

\section{Resin System}

In the matrix system used in the study, MGS L 160 epoxy resin and MGS H 160 hardener produced by HEXION was preferred. This epoxy resin is suitable for manufacturing products according to the vacuum infusion method. In the study, the epoxy/hardener mixing ratio was chosen to be 100:25 by weight, as recommended by the manufacturer (HEXION). Table 3 below shows the properties of the resin, while Table 4 shows the properties of the hardener at room temperatures. 
Table 3. Properties of MGS L 160 resin

\begin{tabular}{|c|c|}
\hline Density $\left(\mathrm{g} / \mathrm{cm}^{3}\right)$ & $1.13-1.17$ \\
\hline Viscosity (mPa.s) & $700-900$ \\
\hline Epoxy Equivalent (g/equivalent) & $166-182$ \\
\hline Epoksi Value (equivalent/100g) & $0.55-0.60$ \\
\hline Refractory Index & $1.548-1.553$ \\
\hline
\end{tabular}

Table 4. Properties of MGS H 160 hardener

\begin{tabular}{|c|c|}
\hline Density $\left(\mathrm{g} / \mathrm{cm}^{3}\right)$ & $0.96-1.0$ \\
\hline Viscosity $(\mathrm{mPa} . \mathrm{s})$ & $10-50$ \\
\hline Amin Value $(\mathrm{mg} \mathrm{KOH} / \mathrm{g})$ & $550-650$ \\
\hline Refractory Index & $1.520-1.521$ \\
\hline
\end{tabular}

\section{Silane Coupling Agents}

In this study, 3-aminopropyltriethoxysilane (APTES) and 3aminopropylmethyldimethoxysilane (APMDMS) produced by Gelest company were used as the coupling agents in the epoxy resin system with $95 \%$ concentration and colorless liquid. Both silane chemical properties are given in Table 5 below.

Table 5. Properties of silane coupling agents

\begin{tabular}{|c|c|c|}
\hline Type of silane & $\begin{array}{c}\text { 3-aminopropyltriethoxysilane } \\
\text { (APTES) }\end{array}$ & $\begin{array}{c}\text { 3-aminopropylmethyldimethoxysilane } \\
\text { (APMDMS) }\end{array}$ \\
\hline Molecular Formula & $\mathrm{C}_{9} \mathrm{H}_{23} \mathrm{NO}_{3} \mathrm{Si}$ & $\mathrm{C}_{8} \mathrm{H}_{22} \mathrm{~N}_{2} \mathrm{O}_{2} \mathrm{Si}$ \\
\hline $\begin{array}{c}\text { Molecular Weight } \\
(\mathrm{g} / \mathrm{mol})\end{array}$ & 221.37 & 206.36 \\
\hline $\begin{array}{c}\text { Density } \\
\left(\mathrm{g} / \mathrm{cm}^{3} \text { at } 25^{\circ} \mathrm{C}\right)\end{array}$ & 0.946 & 0.975 \\
\hline Boiling Point $\left({ }^{\circ} \mathrm{C}\right)$ & 217 & 265 \\
\hline Physical Condition & Liquid, colourless, odourless & Liquid, colourless, odourless \\
\hline
\end{tabular}




\section{Modification of the Matrix System}

In this study, silane coupling agents were separately mixed with the epoxy resin system in order to attain matrix modification. For the modification of the matrix system, the epoxy matrix was modified by silane coupling agents. The percentage of the silane concentration started from 0.0 wt $\%$ to $1.0 \mathrm{wt} \%$ by increasing $0.25 \%$ for this study. Specimens were prepared for the mechanical testing (tensile, impact, and flexural) in order to understand the optimum concentration percentage of silane coupling agents (APTES and APMDMS). They were separately added to the epoxy matrix and mixed for $5 \mathrm{~min}$ at least during the composite production process. After that, the hardener was incorporated into the mixture, which was stirred for approximately $10 \mathrm{~min}$.

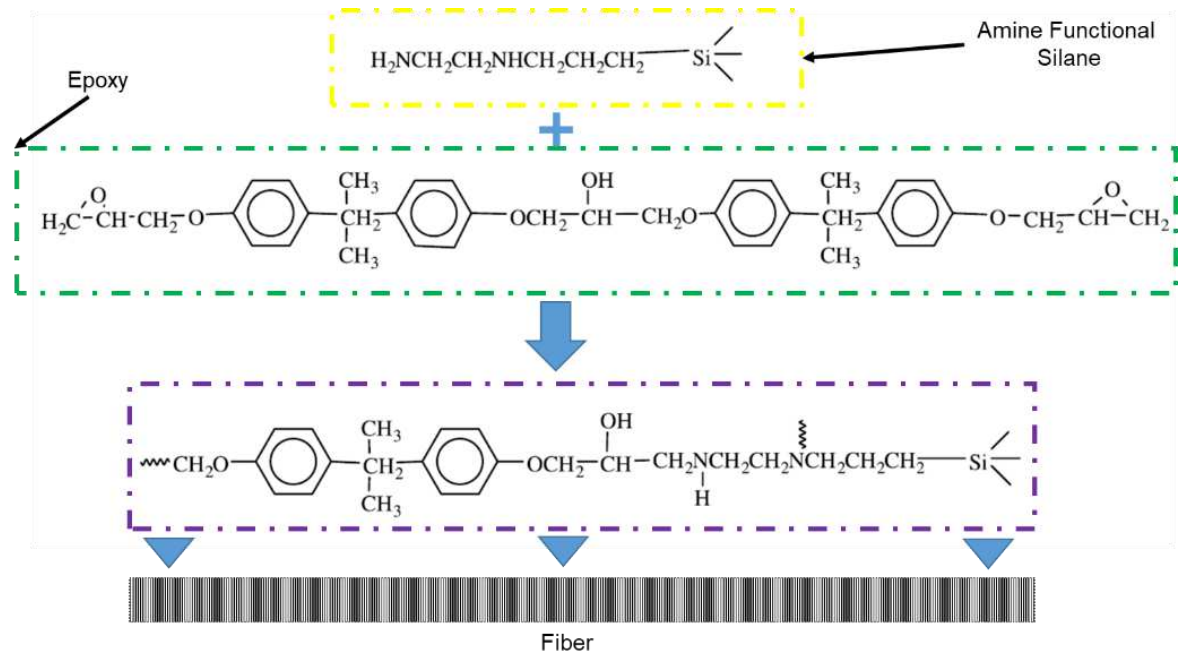

Figure 3. General reaction mechanism between silane coupling agent/epoxy resin/fiber [22]

\section{Production of the Composite Laminate Materials}

Carbon braided composite laminates were produced by the vacuum-assisted resin infusion method (VARIM). The glass mold was cleaned with propanol and the inside of the glass surface covered with releasing agent for easier separation of the composite structure from the mold. There are some production points that need to be taken into account for the vacuum infusion technique. The amount of the resin should be calculated very carefully. If there is not enough resin, then the sample may not reach the desired fiber volume fraction along with voids and 
unclear areas in the composite structure. Hence, this may cause the strength reduction of the composite. In order to achieve healthy test results, there is a minimum thickness required that needs to be calculated for the laminate according to the standard DIN EN ISO 527-4 [23].

$n_{\min }=\frac{F_{R} * h_{\min }}{h_{p l y}} \quad$ Eq. 3.

Where $n_{\min }$ is minimum ply quantity, $F_{R}$ is reduction factor caused by undulation and vacuum, $h_{\min }$ is the minimum required thickness and $h_{p l y}$ is the thickness of one ply. $h_{p l y}$ is calculated as follows,

$V_{p l y}=\frac{\left(\frac{m_{p l y}}{d_{\text {fiber }}}\right)}{v_{f}} \quad$ Eq. 4.

From Equation 4,

$h_{p l y}=\frac{V_{p l y}}{A_{p l y}} \quad$ Eq. 5.

Where $m_{p l y}$ is the weight of fibers of one-ply, $d_{f i b e r}$ is the density of the fiber, $v_{f}$ is the predetermined volume fraction of the fiber which is approximately 0.5 [24] for the vacuum infusion process, $V_{p l y}$ is the volume of one-ply, and $A_{p l y}$ is the area of the ply.

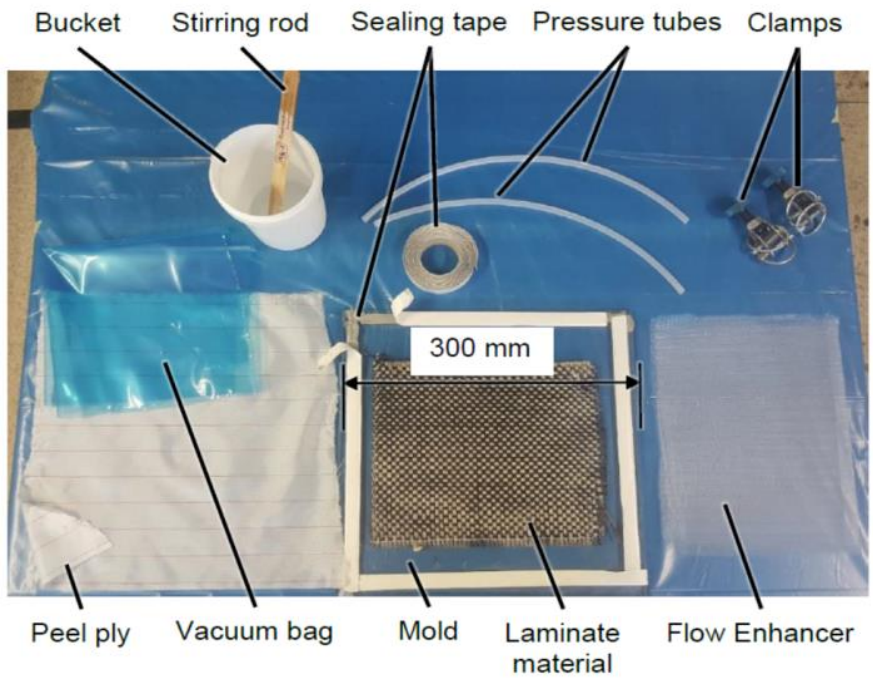


Figure 4. Equipment and braided carbon fabrics used for the vacuum infusion process of the mechanical test sample production

\section{Properties of Produced Composite Materials}

According to the standard for test conditions for isotropic and anisotropic fiber-reinforced plastic composites (DIN EN ISO 527-4) [23], it requires that the thickness of samples should be between 2 and 10 millimeters. Therefore, the number of plies is calculated with the layer calculation equation (Eq. 3) corresponding standard by defining the minimum thickness which is approximately 2 millimeters. The calculated fiber volume fraction for the epoxy/carbon braided samples is approximately 0.55 for this study. It can be seen from the table (Tab. 6) that the error is in the acceptable range. The properties of the epoxy/carbon braided composite plates are shown in Table 6 below.

Table 6. Properties of produced braided composite plates

\begin{tabular}{|c|c|c|c|c|}
\hline $\begin{array}{c}\text { Silane } \\
\text { Concentration } \\
(\%)\end{array}$ & $\begin{array}{c}\text { Number } \\
\text { of Layer }\end{array}$ & $\begin{array}{c}\text { Composite } \\
\text { Thickness } \\
(\mathrm{mm})\end{array}$ & $\begin{array}{c}\text { Fiber } \\
\text { Volume } \\
\text { Fraction }\end{array}$ & $\begin{array}{c}\text { Volume } \\
\text { Fraction } \\
\text { Error }(\%)\end{array}$ \\
\hline None & 4 & 2.11 & 0.55 & 0.081 \\
\hline 0.25 & 4 & 2.09 & 0.54 & 0.083 \\
\hline 0.50 & 4 & 2.08 & 0.54 & 0.084 \\
\hline 0.75 & 4 & 2.12 & 0.56 & 0.082 \\
\hline 1.0 & 4 & 2.10 & 0.55 & 0.079 \\
\hline
\end{tabular}

\section{Tests and Analyzes Applied to Braided Composites}

\section{Tensile Test}

The tensile strength and modulus of the composite structures were tested on the Zwick Z020 tester according to standard DIN EN ISO 527-1 (corresponding to ISO 527) [25]. The testing process was conducted by using a load cell of $200 \mathrm{kN}$ with a speed of $2 \mathrm{~mm} / \mathrm{min}$ at laboratory conditions (temperature $25^{\circ} \mathrm{C}$ and relative humidity of $50 \%$ ). There were five braided test coupons whose length and width was $250 \mathrm{~mm}$ and $25 \mathrm{~mm}$, respectively. In order to determine tensile strain values with more accuracy, Aramis Professional software was used to combine the functionalities of the Aramis camera and GOM Correlate software which allows the user to 
do Digital Image Correlation (DIC). Each test coupon was marked with white dots to measure the elongation for the DIC. While the tensile test was running the Aramis Camera was set to save images with 2 frames per second speed. A total of six facet points were appointed for the white dots on the test coupons which were measured horizontally. The values reported in this study are averages of five successful results most of which were obtained on samples with mentioned specimen size according to standard.

\section{Flexural Test}

The flexural strength and modulus of the composite structures were conducted on the Zwick Z020 tester according to ISO 14125 standard and the test speed was $2 \mathrm{~mm} / \mathrm{min}$ at laboratory conditions (temperature $25^{\circ} \mathrm{C}$ and relative humidity of 50\%) [26]. Five braided test coupons were tested in order to determine the flexural strength and modulus properties of the composite structures. The span-to-depth ratio of flexural strength specimens was 16:1. The data reported in this study are averages of five successful results most of which were acquired from samples according to standard.

\section{Charpy Impact Test}

Charpy impact strength tests of the braided composite were performed at Instron CEAST9050 machine with a $15 \mathrm{~J}$ hammer according to ISO 179-1:2010 standard [27]. Five braided composite specimens were tested in unnotched conditions. The values for impact tests are averages of five successful results.

\section{Fourier Transform Infrared Spectroscopy (FTIR)}

FTIR spectra analysis was carried out using Perkin Elmer - 120 in order to define the spectrum of the silane coupling agent 3 - aminopropyltriethoxysilane (APTES), unmodified and modified epoxy/carbon braided composite samples.

\section{SEM Analysis}

Scanning electron microscopy (SEM) was executed out using an LEO 1450 VP (LEO Electron Microscopy Ltd, Cambridge, UK). These images were obtained by using fractured surfaces resulting from the Charpy impact test. 


\section{RESULTS and DISCUSSION}

\section{Tensile Strength Properties of Braided Composites}

Epoxy-based carbon fiber braided samples were subjected to tensile tests. In this study, the reported data is shown with the confidence interval represented by error bars. Figure 5 shows the tensile strength and tensile modulus of 3 - aminopropyltriethoxysilane (APTES) and 3 aminopropylmethyldimethoxysilane (APMDMS) treated braided carbon composite as a concentration of silane coupling agents which is varied from untreated to $1.0 \mathrm{wt} \%$ by increasing $0.25 \%$.

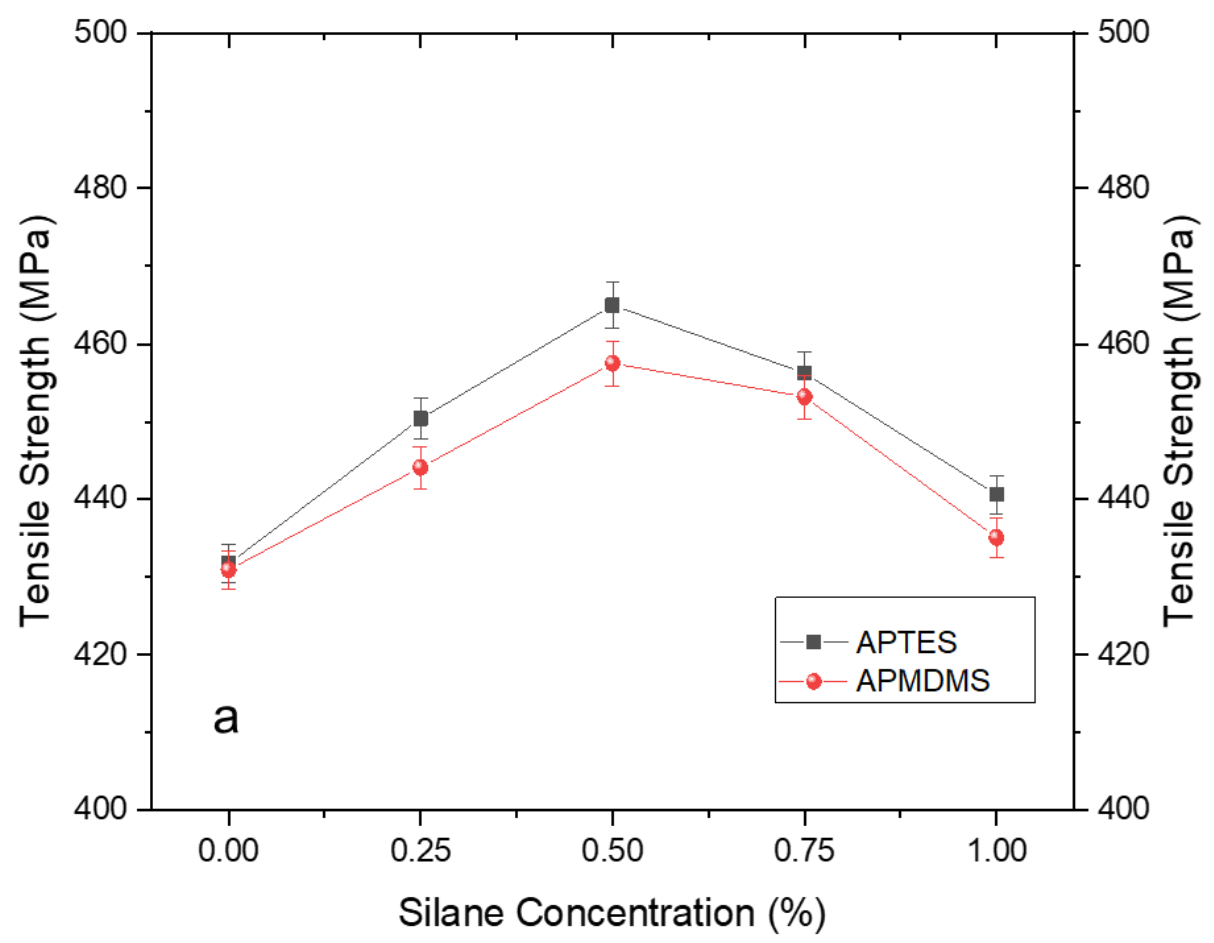




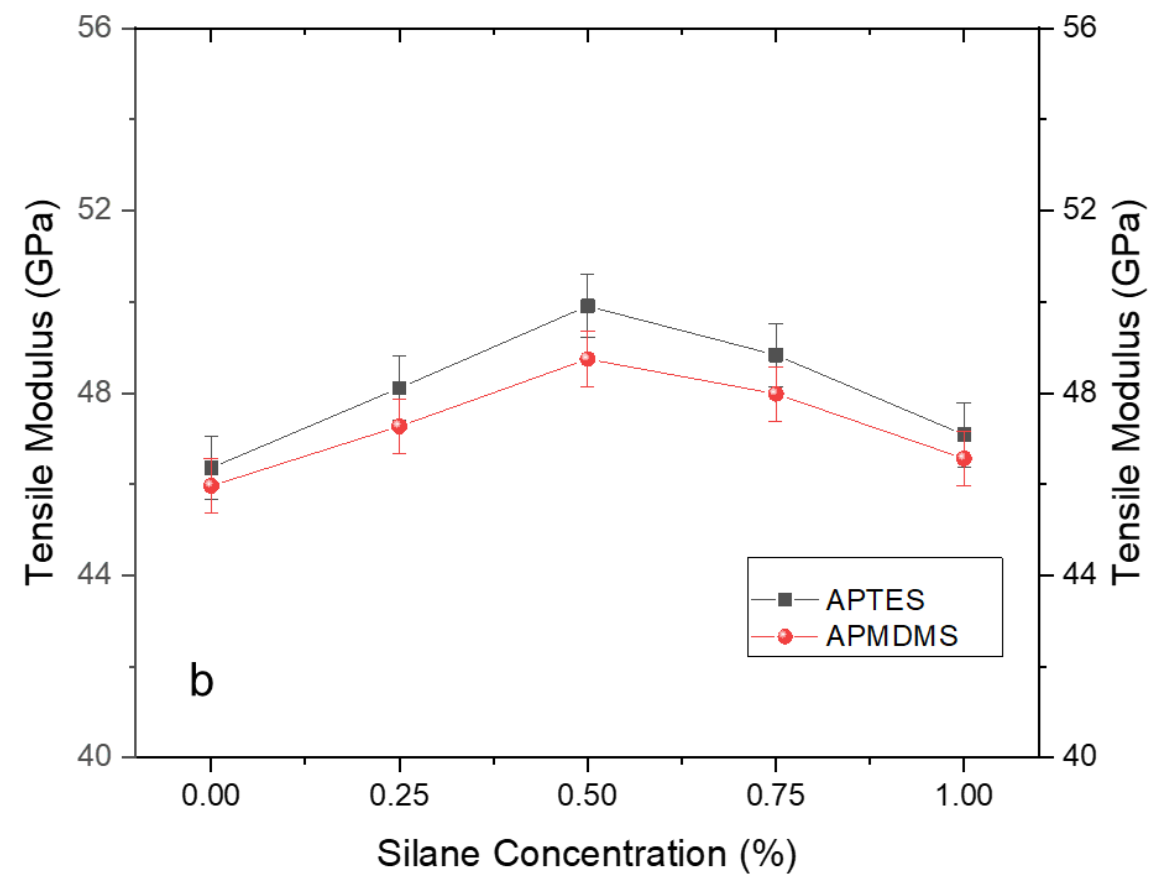

Figure 5. Tensile strength (a) and tensile modulus (b) properties of untreated braided epoxy/carbon composite and silane treated epoxy/carbon composites range from 0.25 to 1.0 wt $\%$

The tensile test results show that the optimum concentration level of both silane coupling agents is $0.5 \mathrm{wt} \%$ (Fig. 5). The strength and modulus value of the APTES-treated braided carbon/epoxy composites are slightly higher than that of the APMDMS-treated braided carbon/epoxy composites at the same concentration. It can be understood from the graphics that the tensile strength and tensile modulus values show an increase. Also, it is clear that the biggest improvement in tensile values for carbon braided composites was achieved with the concentration of $0.5 \mathrm{wt} \%$ for both APTES and APMDMS, which is equal to $464.97 \mathrm{MPa}$, 457.51 MPa for tensile strength and 49.90 GPa, 48.74 GPa for tensile modulus, respectively. The lowest tensile strength values for the silane-modified composites with both silane coupling agents are recorded with the concentration of $1.0 \mathrm{wt} \%$ for both APTES and APMDMS, which corresponds to $440.62 \mathrm{MPa}$ and $435.11 \mathrm{MPa}$, respectively. In terms of tensile modulus, the lowest values are seen with the concentration of $1.0 \mathrm{wt} \%$ for both APTES and APMDMS, 
which are $47.08 \mathrm{GPa}$ and $46.56 \mathrm{GPa}$, respectively. When the silane-treated composite is compared to the untreated composite, the value of tensile strength of $0.5 \mathrm{wt} \%$ APTES and APMDMS is improved up to $7.71 \%$ and $6.16 \%$, respectively. When it comes to the value of tensile modulus for comparison between untreated and silane-treated composites, the value of $0.5 \mathrm{wt} \%$ APTES and APMDMS is gone up to $7.65 \%$ and $6.05 \%$, respectively.

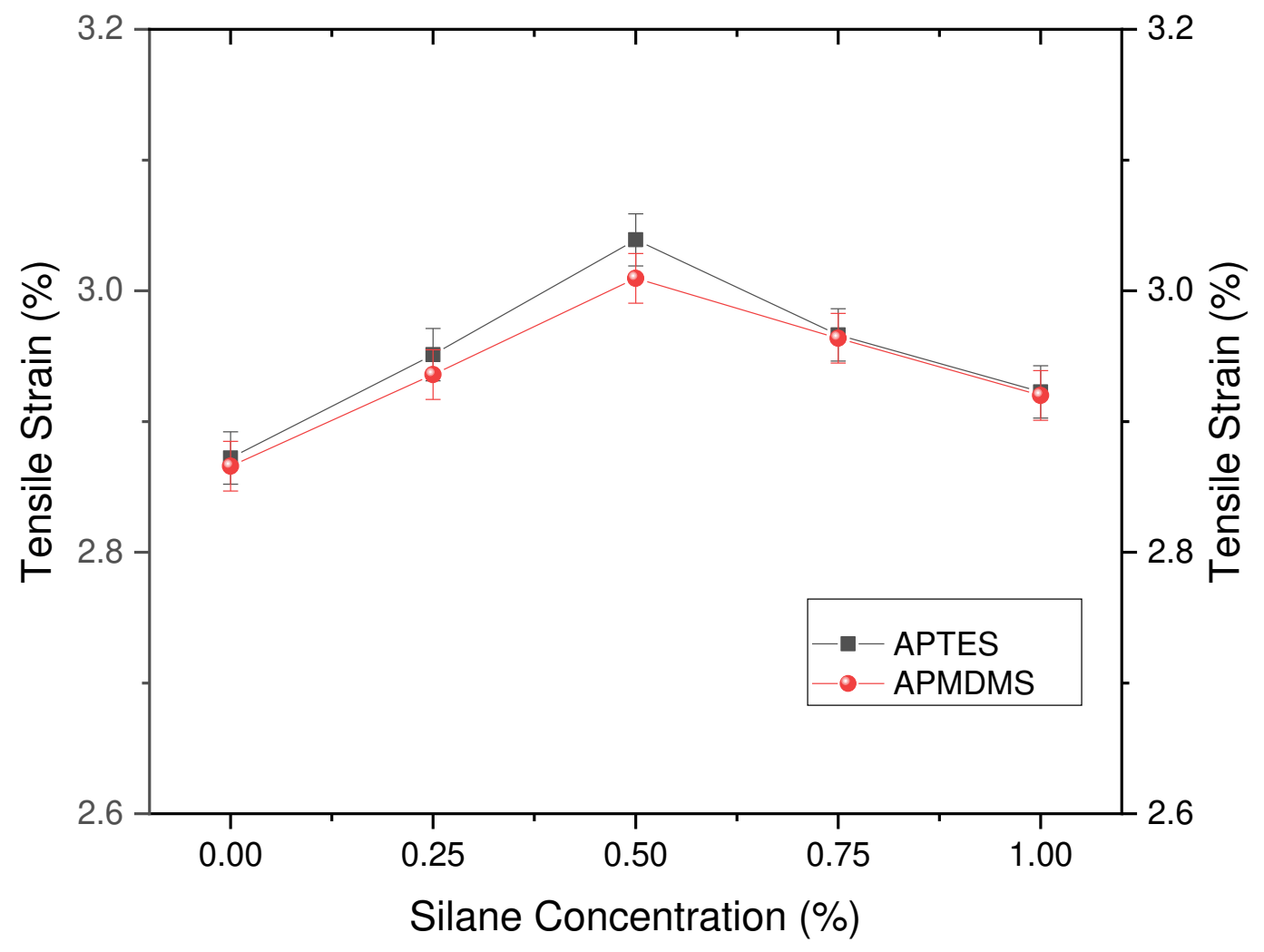

Figure 6. Percentage of tensile strain at break values of untreated braided epoxy/carbon composite and silane treated epoxy/carbon composites range from 0.25 to $1.0 \mathrm{wt} \%$

The effect of silane coupling agents on tensile strain values of the braided carbon/epoxy composites is shown in Figure 6. Strain data showed the maximum tensile strain values of the composite modified with both the APTES and APMDMS are 3.03\% and 3.01\% at the optimum concentration $(0,5 \mathrm{wt} \%)$, respectively. The lowest values for modified epoxy/carbon braided are $2.93 \%$ for APTES and $2.91 \%$ for APMDMS at $1.0 \mathrm{wt} \%$ silane concentration. 
Considering values obtained from the tensile analysis; tensile strength, modulus, and strain values increase gradually with the incrementation of silane concentration until it reaches the optimum value which is $0.5 \mathrm{wt} \%$ for both coupling agents in this study. However, after they come to the optimum value, they decrease with the increase of silane concentration for both of the coupling agents. It is thought that the most important factors affecting the tensile strength in textile-reinforced composite structures are single fiber strength and fiber volume fraction $[28,29]$. For this reason, a slight improvement in the tensile strength properties of carbon braided composite materials has been achieved in the modification process with silane which can be interpreted by the enhancement of adhesive features between carbon fiber and epoxy matrix system [30]. It can be also deducted that the increase and subsequent decrease are related to the saturation level of the silane which depends on the fact that the excess silane coupling agent can generate a weak boundary structure after optimum silane agent concentration [31].

\section{Flexural Strength Properties of Braided Composites}

The flexural strength tests were executed for all the prepared braided carbon/epoxy composite samples. APTES and APMDMS silane coupling agents were utilized in order to improve the flexural properties of the composites. Because flexural strength properties can represent and summarize some of the mechanic structures of the composite such as compressive and shear loads. The effect of APTES and APMDMS silane coupling agent's concentrations on the braided carbon/epoxy composite properties and the resulting mechanical data of the composites has been examined in terms of the strength, modulus, and strain values. 


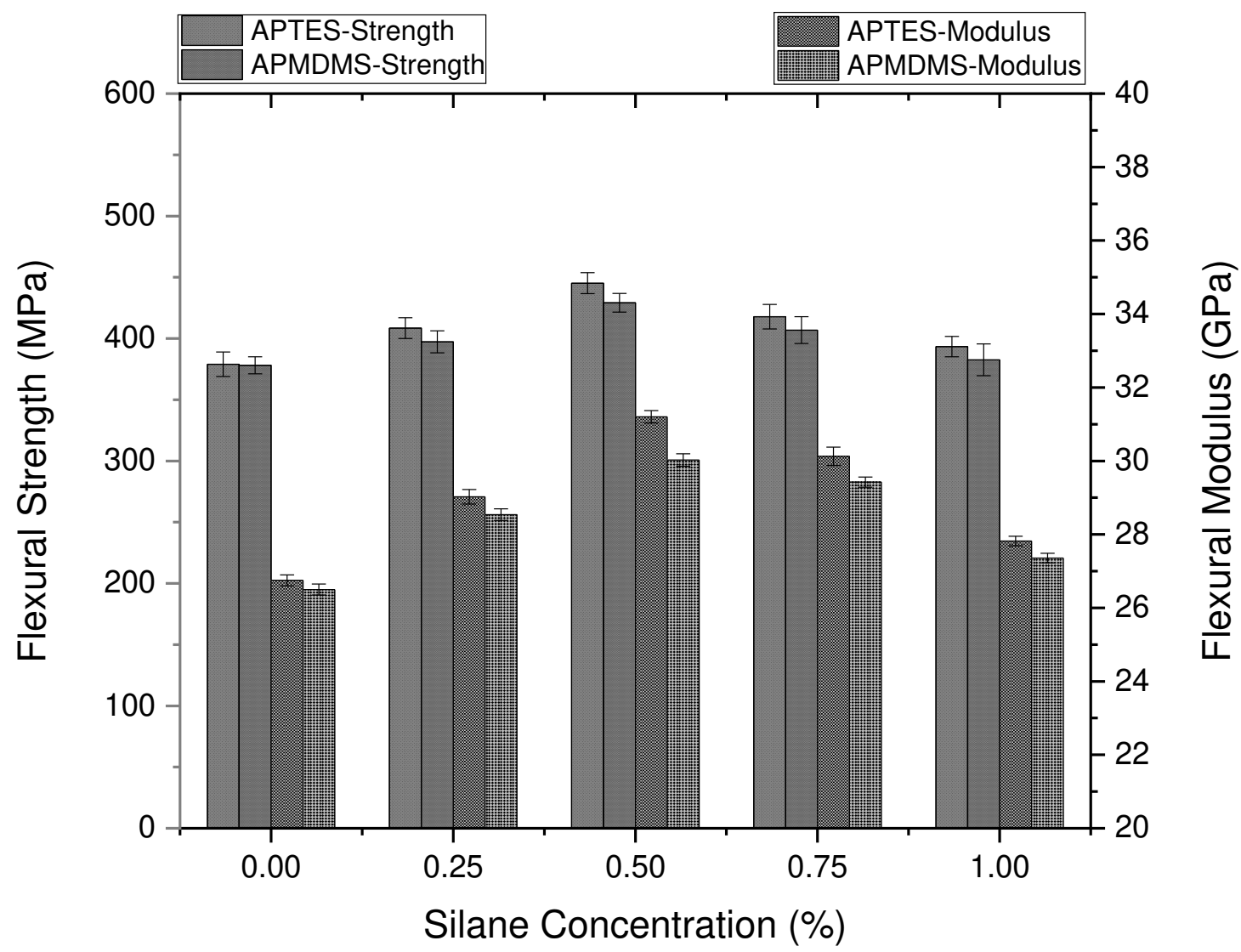

Figure 7. Flexural strength and tensile modulus properties of untreated braided epoxy/carbon composite and silane treated epoxy/carbon composites range from 0.25 to $1.0 \mathrm{wt} \%$

The flexural test results present that the optimum concentration level of both silane coupling agents is $0.5 \mathrm{wt} \%$ for the modified composite materials (Fig. 7). The strength and modulus value of the APMDMS-treated braided carbon/epoxy composites are slightly lower than that of the APTES-treated braided carbon/epoxy composites at the same concentration. It can be interpreted from the figures that the flexural strength and modulus values show an increase. Thus, it is visible that the highest enhancement in flexural values for carbon braided composites was accomplished by the concentration of $0.5 \mathrm{wt} \%$ for both APTES and APMDMS, which is equal to $445.20 \mathrm{MPa}$ and 429.19 $\mathrm{MPa}$ for flexural strength, respectively. When it comes to flexural modulus, the biggest values were obtained by the concentration of $0.5 \mathrm{wt} \%$ for both APTES and APMDMS, which matches $31.20 \mathrm{GPa}$ and $29.89 \mathrm{GPa}$ for flexural modulus, 
respectively. The braided composites that have the lowest flexural strength values for the silanemodified with both silane coupling agents are exhibited with the concentration of $1.0 \mathrm{wt} \%$ for both APTES and APMDMS, which is timely $393.31 \mathrm{MPa}$ and $382.59 \mathrm{MPa}$, respectively. From the point of flexural modulus, the lowest values are seen with the concentration of $1,0 \mathrm{wt} \%$ for both APTES and APMDMS, which are $27.81 \mathrm{GPa}$ and $27.35 \mathrm{GPa}$, respectively. When the silane-treated composite is compared to the untreated composite, the value of flexural strength of $0.5 \mathrm{wt} \%$ APTES and APMDMS is climbed up to $17.48 \%$ and $13.51 \%$, respectively. Concerning flexural modulus comparison between untreated and silane-treated composites, the value of $0.5 \mathrm{wt} \%$ APTES and APMDMS has risen to $16.63 \%$ and $13.33 \%$, respectively.

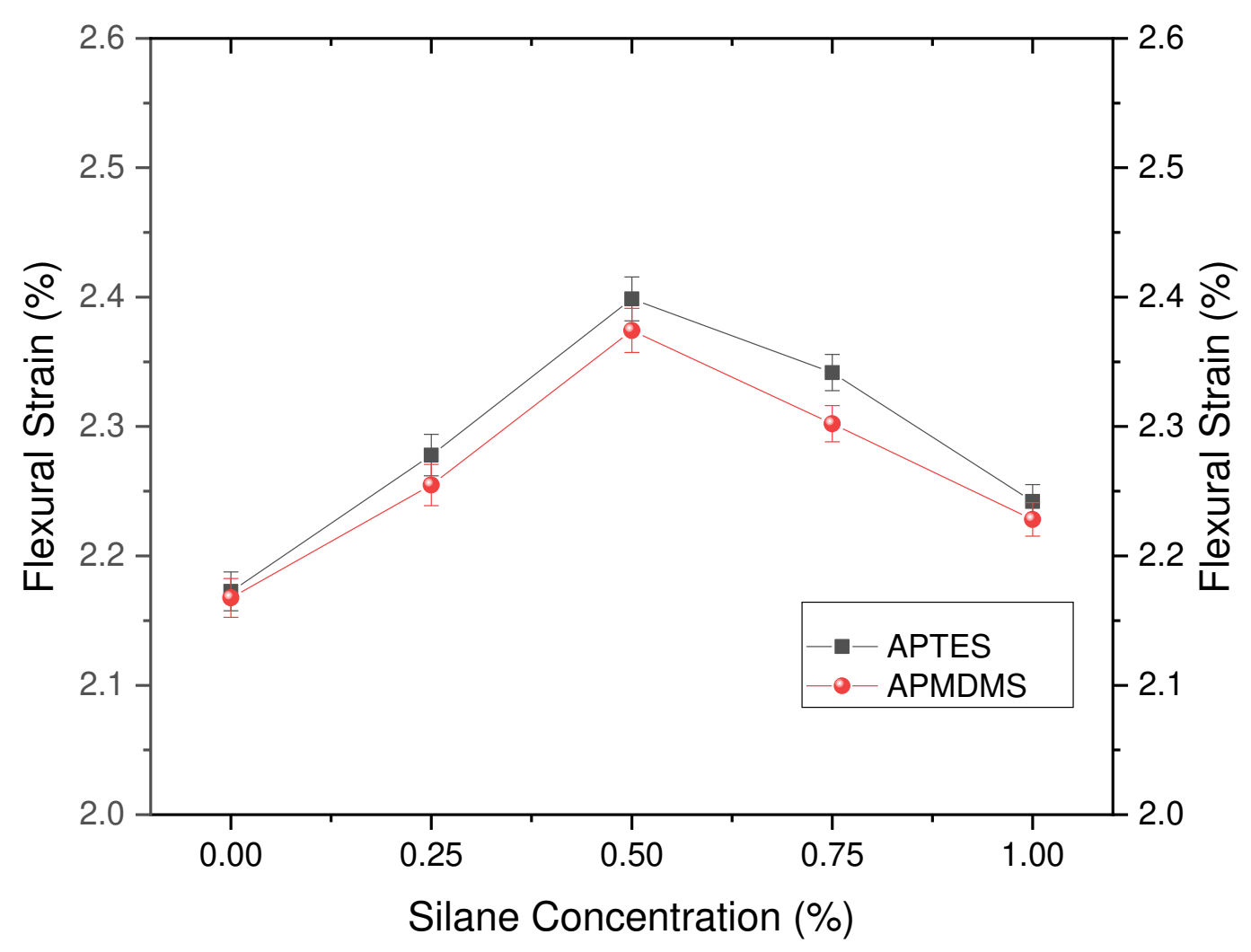

Figure 8. Percentage of flexural strain at break values of untreated braided epoxy/carbon composite and silane treated epoxy/carbon composites range from 0.25 to $1.0 \mathrm{wt} \%$ 
The effect of APTES and APMDMS silane chemicals on flexural strain values of the braided carbon/epoxy composites is shown in Figure 8. The experimental results indicate that the maximum flexural strain values of the composite modified with both the APTES and APMDMS are $3.85 \%$ and $3.80 \%$ at $0.5 \mathrm{wt} \%$, respectively. The lowest flexural strain values for modified epoxy/carbon braided are $2.85 \%$ for APTES and $2.85 \%$ for APMDMS at the highest (1.0 wt $\%$ ) silane concentration.

The flexural properties of epoxy/carbon braided composite are affected by the fiber volume fractions, which is determined by the production process, and adhesion between fiber-matrix component. Proper silane coupling process might lead to improved adhesion which results in better flexural performance at braided composite [16, 32, 33].

\section{Impact Strength Properties of Braided Composites}

Charpy impact test was implemented on unnotched samples and Figure 9 illustrates the related test results. According to the results, the optimum concentration of both silane coupling agents is $0.5 \mathrm{wt} \%$ as like tensile and flexural properties of the braided composites. 


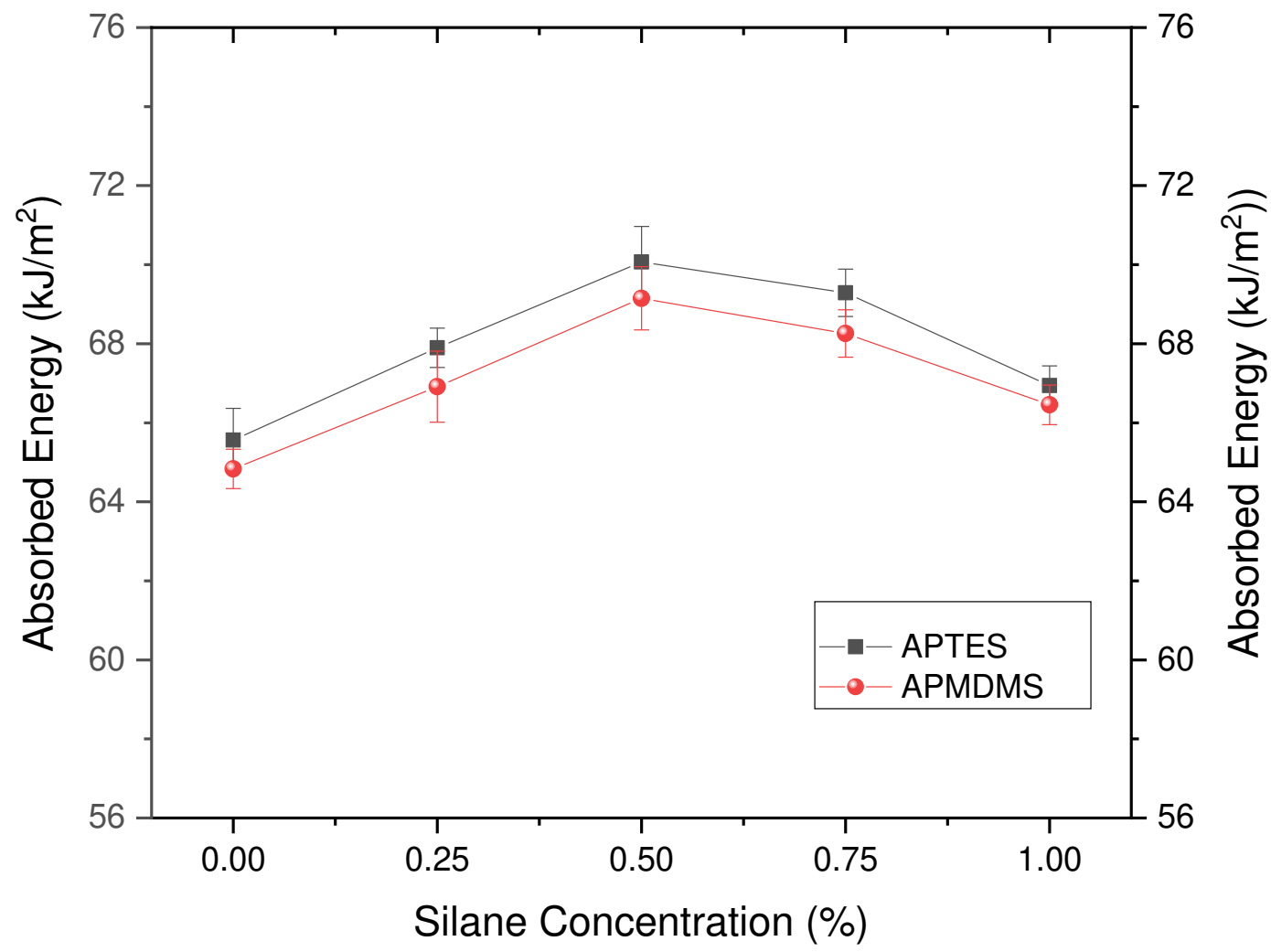

Figure 9. Charpy impact strength results of untreated braided epoxy/carbon composite and silane treated epoxy/carbon composites range from 0.25 to $1.0 \mathrm{wt} \%$ in terms of absorbed energy $\left(\mathrm{kJ} / \mathrm{m}^{2}\right)$

The APTES-treated composite has the highest impact strength value of $70.06 \mathrm{~kJ} / \mathrm{m}^{2}$ with a concentration of $0.5 \mathrm{wt} \%$. The addition of the APMDMS to the braided composites has resulted in a maximum value of $69.14 \mathrm{~kJ} / \mathrm{m}^{2}$ with the same concentration above mentioned. The modification of both silane coupling agents hasn't resulted in a sharp increase $(6.87 \%$ and $4.31 \%$ ) in impact strength. The reason for this might be explained by the fact that a higher amount of fiber reinforcement improves the interfacial strength properties but not the impact resistance of the composite $[34,35]$. The impact resistance of the fiber-reinforced composites is generally affiliated with the specific properties of the fiber and resin system, the amount of impact energy conveyed to the composite sample, and the interface properties of the 
fiber/matrix system [36-38]. The effect mechanism of the fiber material amount on the impact resistance of textile reinforced composites is more sophisticated than tensile and flexural strengths properties due to the impact resistance of energy distribution during stress. The impact energy distribution is very important for matrix cracking, delamination, fiber/matrix debonding, fiber pullout, and fiber rupture modes [39].

\section{FTIR - ATR Analysis}

FT - IR spectra were attained by utilizing the Attenuated Total Reflectance (ATR) module. FTIR-ATR was used for surface functional group analysis of 3-aminopropyltriethoxysilane (APTES) amino-silane coupling agent and its FT-IR spectra are seen in Figure 10. The spectrum of neat APTES peaks is observed between $1574-1576 \mathrm{~cm}^{-1}$ as $\mathrm{N}-\mathrm{H}$ bond. $\mathrm{Si}-\mathrm{C}$ bond between $1296-760 \mathrm{~cm}^{-1}$ and $\mathrm{Si}-\mathrm{O}-\mathrm{C}$ bond between $1072-952$ is seen at the FT-IR spectra analysis of silane agent.

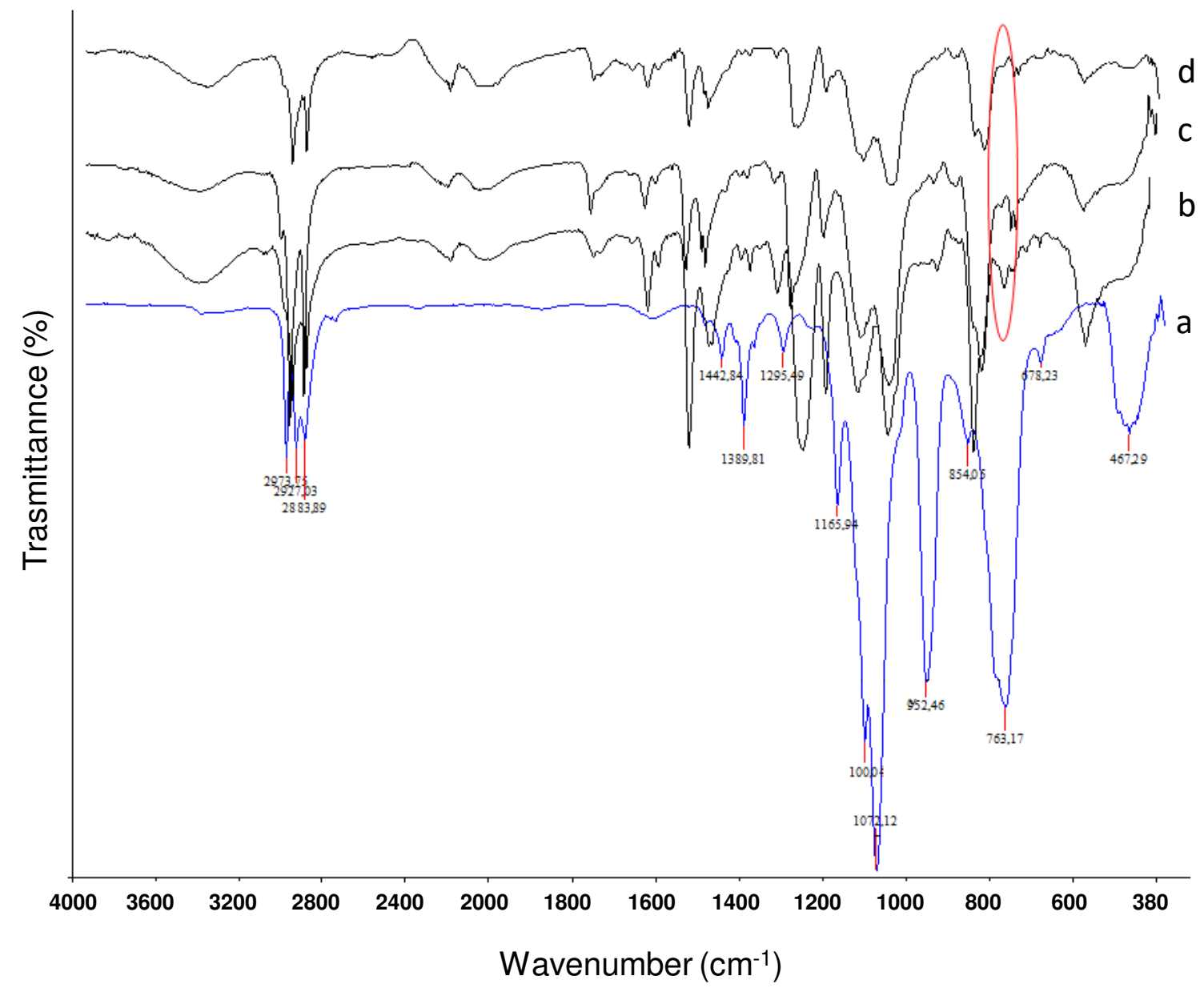


Figure 10. FTIR - ATR spectra of (a) neat 3-Aminopropyltriethoxysilane (APTES) silane coupling agent; (b) $1.0 \mathrm{wt} \%$ APTES-treated epoxy/carbon braided composite; (c) $0.50 \mathrm{wt} \%$ APTES-treated epoxy/carbon braided composite; (d) Epoxy/carbon braided composite without silane treated

Figure 13 presents the spectrum of the samples with $0.50 \mathrm{wt} \%, 1.0 \mathrm{wt} \%$ APTES-treated silane, and epoxy/carbon braided composite without silane treated. When the spectrum is examined, a peak belongs to $\mathrm{Si}-\mathrm{C}$ bond is seen at $763 \mathrm{~cm}^{-1}$ for neat APTES, $0.50 \mathrm{wt} \%, 1.0 \mathrm{wt} \%$ APTEStreated silane epoxy/carbon braided composite samples. On the other hand, the same peak affiliated with $\mathrm{Si}-\mathrm{C}$ bond is not observed at the non-silane treated epoxy/carbon braided composite sample. When the red circle area is observed closely from Figure 11, it can be interpreted that the intensity of the peak of the $\mathrm{Si}-\mathrm{C}$ bond depends on the increase of silane concentration. Because, the depth of $\mathrm{Si}-\mathrm{C}$ for $1.0 \mathrm{wt} \%$ APTES-treated silane composite is higher than the $0.50 \mathrm{wt} \%$ APTES-treated silane composite. It can infer that proper surface modification with silane effectively increase the fiber surface activity by observing this peak.

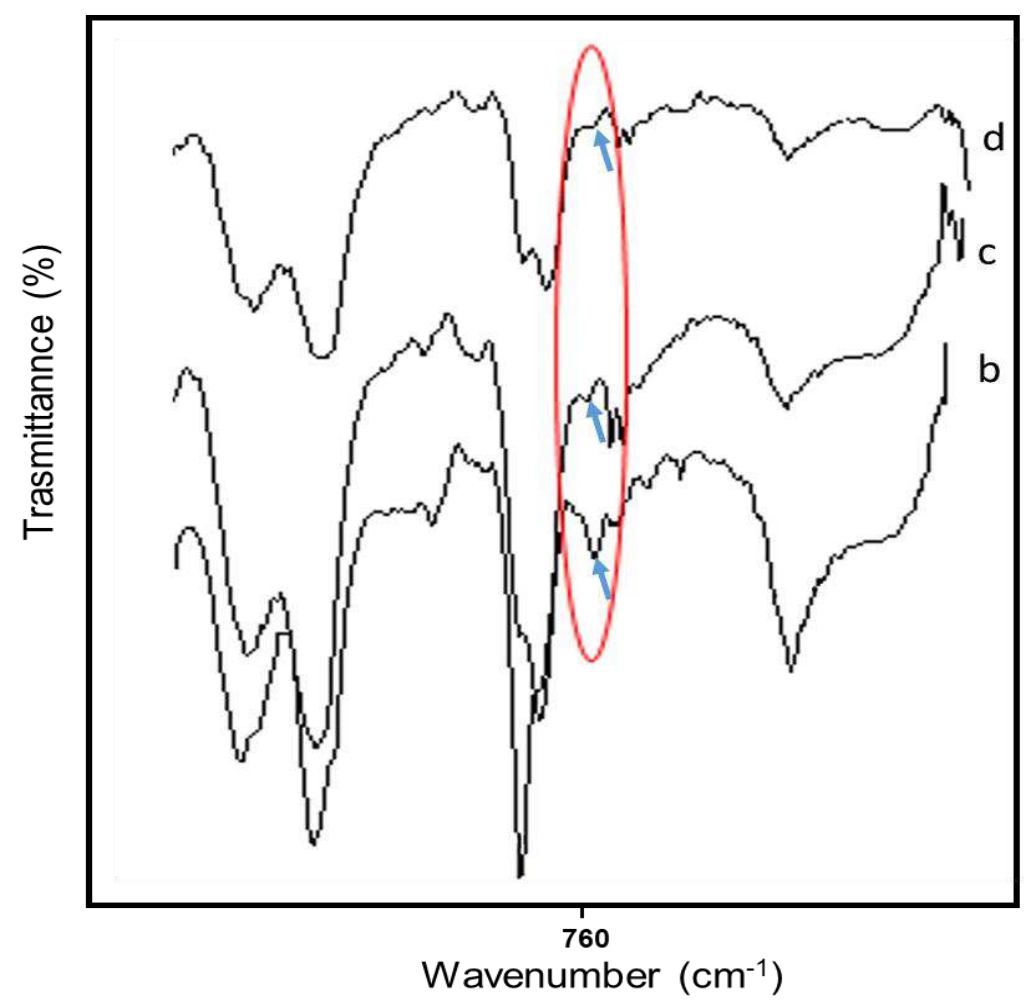


Figure 11. FTIR - ATR spectra closer peak analysis of the (b) $1.0 \mathrm{wt} \%$ APTES-treated epoxy/carbon braided composite; (c) $0.50 \mathrm{wt} \%$ APTES-treated epoxy/carbon braided composite; (d) Epoxy/carbon braided composite without silane treated

\section{Microstructure Properties of Braided Composites}

Scanning electron microscope images were captured for silane-untreated (Fig. 12a), $0.50 \mathrm{wt} \%$ APTES-treated (Fig. 12b), and 0.50 wt\% APMDMS-treated (Fig. 12c) to observe the microstructure of the epoxy-based braided composites. Based on the results of the Charpy impact and the obtained SEM images from the same analysis, the damage types seen in the samples were determined as fiber breakage, fiber peel, matrix pore, and matrix crack. In addition to these damages, matrix residues are seen on the fracture surfaces. With the usage of silane, less fiber pulls out and more fiber breakage is detected because of the improvement in interfacial strength according to the SEM images. 

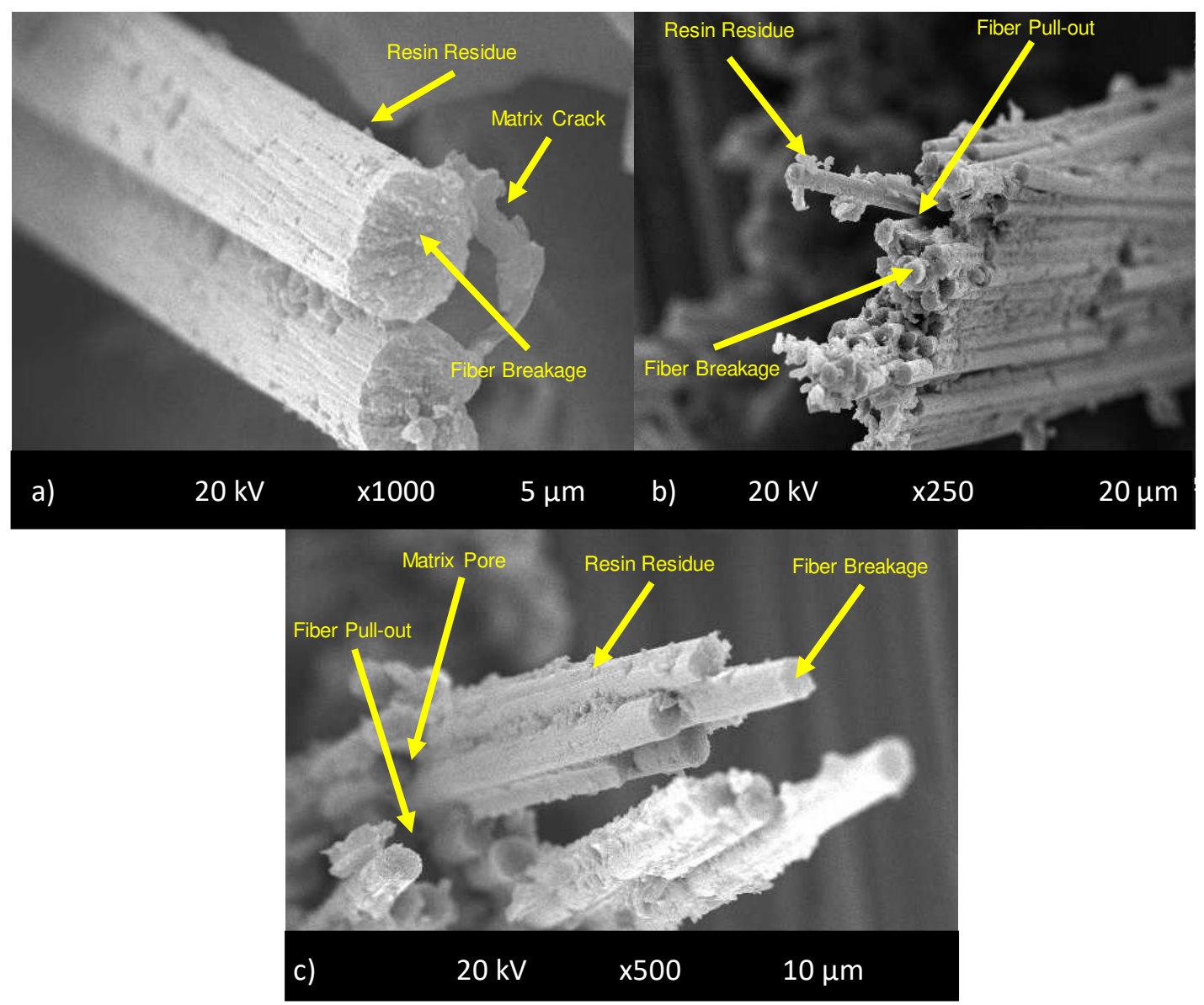

Figure 12. SEM morphologies of the fractured surface's epoxy/braided carbon composites after Charpy impact testing: a) silane untreated; b) $0.50 \mathrm{wt} \%$ APTES-treated; c) $0.50 \mathrm{wt} \%$ APMDMS-treated samples

The fracture surfaces of the epoxy braided carbon composites exhibit various outputs stemming from modification of fiber/matrix with silane coupling agent as represented in Figure 12. When the surface of fracture for silane untreated epoxy composite is examined, it can be observed that less amount of epoxy resin is spotted to adhere onto the fiber surfaces which seems smoother and cleaner comparison with the other two silane treated epoxy braided carbon composites. It can be said that the adhesion between the epoxy resin and carbon fiber is weaker than the others (Fig. 12a).

After modification of the matrix with $0.50 \mathrm{wt} \%$ APTES silane, SEM images show that a greater amount of epoxy resin is detected at the fiber surfaces in comparison to silane untreated braided 
carbon composite and this situation also applies to $0.50 \mathrm{wt} \%$ APMDMS-treated samples (Fig. $12 \mathrm{~b}$ and Fig. 12c). That is to say, decent modification of carbon fiber with silane coupling agents increases the interfacial adhesion that leads to improving the mechanical performance of the braided carbon composites. Moreover, these observations can be proved by the results of the tensile strength, flexural strength, and impact resistance analysis.

\section{CONCLUSIONS}

Two types of silane coupling agents (APTES and APMDMS) were selected to treat epoxy /carbon braided fabrics. APTES and APMDMS were utilized in order to enhance the interfacial bond between the matrix system (epoxy resin) and reinforcing fiber system (carbon fiber). The mechanical properties of the composite structures were analyzed from the point of tensile strength, flexural strength, and Charpy impact strength. Both silane-treated and non-treated composites were confirmed by FTIR-ATR analysis and also visualized by the technique of SEM images.

In this present study, the mechanical properties of epoxy/carbon braided composites decreased above $0.5 \mathrm{wt} \%$ silane concentration. This is related to the fact that the excess amount of silane, which causes a lubrication effect, constitutes the weak boundary layer after optimum $(0.5 \mathrm{wt} \%)$ silane coupling agent concentration. So, all the mechanical properties (tensile, flexural, and impact) of the composites have shown a decrease at higher silane concentrations.

When all mechanical test results are examined, APTES-treated epoxy/carbon braided composites in all concentrations have resulted slightly better than APMDMS-treated epoxy/braided carbon composites. It is thought that the reason for this situation can be explained by the less branched network and more closed/packed structure for APTES that results in slightly better mechanical performance on braided composited compared to APMDMS [22, 40].

According to the results of tensile analysis, the tensile strength of the epoxy/carbon braided composite could be improved by both silane coupling agents treatment. However, when it is compared to untreated braided composite, this improvement was limited with $7.71 \%$ and $6.16 \%$ in tensile strength value for optimum concentration which is $0.5 \mathrm{wt} \%$ both APTES and $0.5 \mathrm{wt} \%$ APMDMS, respectively. In terms of tensile modulus, analogous improvement wasn't able to pass $7.65 \%$ and $6.05 \% 0.5 \mathrm{wt} \%$ APTES and $0.5 \mathrm{wt} \%$ APMDMS, respectively. 
When it comes to the flexural properties of these epoxy/carbon braided composites, the enhancement has resulted in $17.48 \%$ and $13.51 \%$ for the optimum concentration of both APTES and APMDMS in flexural strength value, and the analogous enhancement of flexural modulus has occurred with $16.63 \%$ and $13.33 \%$, respectively. Specimens with APMDMStreated tend to have slightly lower flexural strength and modulus compared to APTES-treated ones.

The effect of the silane coupling process on Charpy impact strength is slightly enhanced by $6.87 \%$ and $4.31 \%$ for the optimum concentration of both APTES and APMDMS, respectively. The reason for the slight increase can be also linked to that the improvement in interfacial adhesion modified by silane coupling agents has a slight effect on the impact strength of the braided carbon composites. It is thought the effect of interfacial adhesion on impact strength is negligible level.

In summary, the proper silanization process has good compatibility with the epoxy matrix system and so this situation increased the interfacial adhesion between braided carbon fiber and epoxy matrix that results in better mechanical performance on composite structures.

\section{Availability of data and materials}

The data that support the findings of this study are available on request from the corresponding author [OE].

\section{Competing interests}

The authors declare that they have no competing interests.

\section{Authors' contributions}

OE was in charge of the whole trial and made mechanical analysis. ES assisted for the vacuum infusion production process and sampling of braided composites. OE wrote the manuscript. Both authors read and approved the final manuscript.

\section{Authors' Information}

Oguz ERYILMAZ, born in 1989, is currently a Ph.D. candidate at Marmara University, Department of Textile Engineering. His research area is textile-reinforced composites which are specifically for braided tubular composite. Also, he is currently working on a composite 
braided pressure vessel production project at ITA (Institut für Textiltechnik) RWTH Aachen University.

Erhan SANCAK, born in 1978, is an associate professor at Marmara University, Department of Textile Engineering. He gives a lecture about textile-reinforced composite in the same department. His main research includes textile preform production, technical textile, and mechanical properties of the composites.

\section{Authors' Detail}

${ }^{1}$ Department of Textile Engineering, Faculty of Technology, Marmara University, Kadikoy, Istanbul, 34720 Turkey

\section{Funding}

This study is supported and funded by the Scientific Research Projects Department of Marmara University (MU-BAPKO) under the grant [FDK-2020-10037].

\section{Acknowledgement}

The authors would like to acknowledge the support of the Tubular Composite Department at ITA (Institut für Textiltechnik) RWTH Aachen University for this present study.

\section{REFERENCES}

1. Dexter, H.B. and G.H. Hasko, Mechanical properties and damage tolerance of multiaxial warp-knit composites. Composites Science and Technology, 1996. 56(3): p. 367-380.

2. Lomov, S.V., et al., Textile geometry preprocessor for meso-mechanical models of woven composites. Composites Science and Technology, 2000. 60(11): p. 2083-2095.

3. Newcomb, B.A., Processing, structure, and properties of carbon fibers. Composites Part A: Applied Science and Manufacturing, 2016. 91: p. 262-282.

4. Chand, S., Review Carbon fibers for composites. Journal of Materials Science, 2000. 35(6): p. 1303-1313.

5. Kyosev, Y., 1 - Introduction: the main types of braided structure using maypole braiding technology, in Braiding Technology for Textiles, Y. Kyosev, Editor. 2015, Woodhead Publishing. p. 1-25. 
6. Ayranci, C. and J. Carey, 2D braided composites: A review for stiffness critical applications. Composite Structures, 2008. 85(1): p. 43-58.

7. Liao, T. and S. Adanur, 3D Structural Simulation of Tubular Braided Fabrics for NetShape Composites. Textile Research Journal, 2000. 70(4): p. 297-303.

8. Kyosev, Y., 3 - Structural design of flat and tubular braids, in Braiding Technology for Textiles, Y. Kyosev, Editor. 2015, Woodhead Publishing. p. 47-69.

9. Iwashita, N., E. Psomiadou, and Y. Sawada, Effect of coupling treatment of carbon fiber surface on mechanical properties of carbon fiber reinforced carbon composites. Composites Part A: Applied Science and Manufacturing, 1998. 29(8): p. 965-972.

10. Sakai, M., T. Miyajima, and M. Inagaki, Fracture toughness and fiber bridging of carbon fiber reinforced carbon composites. Composites Science and Technology, 1991. 40(3): p. 231-250.

11. Reale Batista, M.D. and L.T. Drzal, Carbon fiber/epoxy matrix composite interphases modified with cellulose nanocrystals. Composites Science and Technology, 2018. 164: p. 274-281.

12. Zhang, Y., et al., (3-aminopropyl) triethoxysilane grafted poly(dopamine)Fe3O4 nanoparticles and their epoxy composites for functional application. Composites Part B: Engineering, 2019. 169: p. 148-156.

13. Zhang, M., et al., Co-depositing bio-inspired tannic acid-aminopropyltriethoxysilane coating onto carbon fiber for excellent interfacial adhesion of epoxy composites. Composites Science and Technology, 2021. 204: p. 108639.

14. Plueddemann, E.P., Performance of Silane Coupling Agents, in Silane Coupling Agents, E.P. Plueddemann, Editor. 1982, Springer US: Boston, MA. p. 141-165.

15. Yu, S., et al., The effect of amino-silane coupling agents having different molecular structures on the mechanical properties of basalt fiber-reinforced polyamide 6,6 composites. Composites Part B: Engineering, 2019. 163: p. 511-521.

16. Yang, J., et al., Matrix modification with silane coupling agent for carbon fiber reinforced epoxy composites. Fibers and Polymers, 2013. 14(5): p. 759-766.

17. Arold, B., et al., 1 - Braiding processes for composites manufacture, in Advances in Composites Manufacturing and Process Design, P. Boisse, Editor. 2015, Woodhead Publishing. p. 3-26. 
18. Kyosev, Y., 2 - Patterning of braided products, in Braiding Technology for Textiles, Y. Kyosev, Editor. 2015, Woodhead Publishing. p. 29-46.

19. Melenka, G.W., et al., 3 - Manufacturing processes for braided composite materials, in Handbook of Advances in Braided Composite Materials, J.P. Carey, Editor. 2017, Woodhead Publishing. p. 47-153.

20. Lengersdorf, M., J. Multhoff, and T. Gries. Braiding: A New Production Method Approach for Composite Pressure Vessels in Automotive Applications. in ASME 2014 Pressure Vessels and Piping Conference. 2014.

21. Lyons, J. and C.M. Pastore, Effect of braid structure on yarn cross-sectional shape. Fibers and Polymers, 2004. 5(3): p. 182.

22. Xie, Y., et al., Silane coupling agents used for natural fiber/polymer composites: A review. Composites Part A: Applied Science and Manufacturing, 2010. 41(7): p. 806819.

23. ISO 527-4, I., Plastics - Determination of tensile properties - Part 4: Test conditions for isotropic and orthotropic fibre-reinforced plastic composites. 1997.

24. Liu, Y.-N., et al., Study on the resin infusion process based on automated fiber placement fabricated dry fiber preform. Scientific Reports, 2019. 9(1): p. 7440.

25. ISO 527-1, I., Plastics - Determination of tensile properties - Part 1: General principles. 2019.

26. ISO 14125, I., Fibre-reinforced plastic composites - Determination of flexural properties. 1998.

27. ISO 179-1, I., Plastics - Determination of Charpy impact properties - Part 1: Noninstrumented impact test. 2010.

28. Fu, S.Y., et al., Tensile properties of short-glass-fiber- and short-carbon-fiberreinforced polypropylene composites. Composites Part A: Applied Science and Manufacturing, 2000. 31(10): p. 1117-1125.

29. $\mathrm{Gu}, \mathrm{W}$., et al., Volume fraction effects on interfacial adhesion strength of glass-fiberreinforced polymer composites. Materials Science and Engineering: A, 2000. 277(1): p. 237-243. 
30. Li, J., Effect of Silane Coupling Agent on the Tensile Properties of Carbon FiberReinforced Thermoplastic Polyimide Composites. Polymer-Plastics Technology and Engineering, 2010. 49(4): p. 337-340.

31. Saidpour, S.H. and M.O.W. Richardson, Glass fibre coating for optimum mechanical properties of vinyl ester composites. Composites Part A: Applied Science and Manufacturing, 1997. 28(11): p. 971-975.

32. Ary Subagia, I.D.G., et al., Effect of stacking sequence on the flexural properties of hybrid composites reinforced with carbon and basalt fibers. Composites Part B: Engineering, 2014. 58: p. 251-258.

33. Yuan, H., et al., Investigation of flexural properties and failure behaviour of biaxial braided CFRP. Polymer Testing, 2020. 87: p. 106545.

34. Hong, S.W., et al., Charpy impact fracture characteristics of CFRP composite materials according to variations of fiber array direction and temperature. International Journal of Precision Engineering and Manufacturing, 2013. 14(2): p. 253-258.

35. Chou, S., H.-C. Chen, and H.-E. Chen, Effect of weave structure on mechanical fracture behavior of three-dimensional carbon fiber fabric reinforced epoxy resin composites. Composites Science and Technology, 1992. 45(1): p. 23-35.

36. Li, D.-s., et al., Charpy impact properties and failure mechanism of $3 D$ MWK composites at room and cryogenic temperatures. Cryogenics, 2014. 62: p. 37-47.

37. Eslami-Farsani, R., S.M. Reza Khalili, and M. Najafi, Effect of Thermal Cycling on Hardness and Impact Properties of Polymer Composites Reinforced by Basalt and Carbon Fibers. Journal of Thermal Stresses, 2013. 36(7): p. 684-698.

38. Oval1, S. and E. Sancak, Investigation of Mechanical Properties of Jute Fiber Reinforced Low Density Polyethylene Composites. Journal of Natural Fibers, 2020: p. $1-18$.

39. Arslan, C. and M. Dogan, The effects of silane coupling agents on the mechanical properties of basalt fiber reinforced poly(butylene terephthalate) composites. Composites Part B: Engineering, 2018. 146: p. 145-154.

40. Serier, A., J.P. Pascault, and T.M. Lam, Reactions in aminosilane-epoxy prepolymer systems. II. Reactions of alkoxysilane groups with or without the presence of water. Journal of Polymer Science Part A: Polymer Chemistry, 1991. 29(8): p. 1125-1131. 
